\title{
Low Friction Clutch Using Planetary Gears and Cams Mechanisms (Part I: Idea and Preliminary Design)
}

\author{
Khaled M. Khader \\ Production Engineering and Mechanical Design Department, Faculty of Engineering \\ Menoufia University, Shebin El-kom, Menoufia, Egypt \\ (Corresponding author: khkhm62@hotmail.com)
}

\begin{abstract}
Research progress in the automotive industry sector is highly motivated by scarcity and rapid depletion of the fossil fuels. Hence, designing automotive components that could support decreasing power losses is critical to efficient use of fuel. Clutches are basic elements in automotive industries for controlling motion transmission. Furthermore, loss of power related to the "spin loss" phenomenon in clutches significantly affects the motion transmission efficiency. "Thereforeautomotive industryard to developers are looking forw develop advanced clutchesthat yield to low losses associated with quick response. The friction in clutches' disks is a main source of power losses. Also, the friction affects the clutches life time which causes sudden troubles.

This paper presents a conceptual design of low friction clutch using permanent magnet cylinders, planetary gears and cams mechanisms for reducing loss of power in order to improve system efficiency. This clutch uses the magnetic forces effect of magnetic cylinders instead of the direct contact effect of the regular clutch's friction disks. Also, this clutch is provided with cams mechanism for assuring that motion is completely stopped. Moreover, planetary gears of this clutch decrease rotation speed and increase torque as an initial reduction gear box. Finally, a prototype of this clutch is presented for testing the conceptual design validity.
\end{abstract}

Keywords: Mechanism; Cams; Clutch Design; Planetary Gears.

\section{Introduction}

Motor fuel is playing an important role in automotive industries development. Unfortunately, it is impossible to ensure stable availability of motor fuel because of the rapid depletion of fossil fuels. Accordingly, controlling power losses attracted the attention of automotive industry specialists through the recent decades. Motion transmission can be controlled using clutches which are considered one of the main effective elements in the automotive industries. Unluckily, the friction of the direct contact in clutches elements is a main source of power losses which decreases the clutches life time.

Generally, the main essential requirements of clutches are torque transmission with an acceptable dynamic balancing and vibrating damping in addition to gradual engagement. There are many popular types of clutches such as friction clutch, wet clutch, centrifugal clutch, hydraulic clutch and electromagnetic clutch. In addition to the previous types, there are also special ones such as spline clutch, vacuum clutch or free-wheel unit clutch as mentioned by Johanson and Duffy [1]. Optimizing friction behavior of clutch facings has been tested and presented using pinion-disk test by Khamlichi et al., [2]. Additionally, a rational approach based on special technique is used to study behavior of clutch facings friction coefficient.

Some ideas have been presented to develop the clutchs design. For example, mechanical clutch designed by Chopra et al. [3], is designed in order to minimize energy consumption through using high performance screw joint and built-in locking mechanism. This mechanical clutch consists of actuator, brushless DC motor, lead screw shaft, clutch apply-plate and set of wet clutch disks.

Furthermore, many of the pervious scientific works have focused on the reasons of power loss in clutches in order to propose appropriate solutions to decrease the loss of power as much as possible. Some of the scientific works explored innovative designs for increasing the clamping forces in order to improve the clutch systems efficiency (Xu and King, [4]; Neelakantan et al., [5]). These papers introduced 
electromechanical systems using piezoelectric actuators for providing very high clamping forces. Also, adaptive force control with self-energizing effect of clutch actuator is presented by Kim and Choi [6]. In addition, a control scheme with selfenergizing mechanism is developed for the clutch actuator system dealing with sliding mode control. Clutches can be classified into wet and dry clutches according to the existence of lubrication fluid. Drag torque prediction model of the wet clutch was investigated by Jibin et al., [7]. Drag torque gradually increases until its maximum value is reached at a critical rotational speed, then it decreases at a certain speed above the critical one due to the reduction of oil film area.

The effect of lubricant fluid flow on drag torque of a wet clutch has been investigated by Takagi et al., [8]. They indicated that the drag torque reached its maximum value after lubricant fluid bubbles appeared through the clutch disks. Moreover, the torque steadily decreases when the bubbles covered the surface of the clutch. A model of dual clutch's drag torque is developed for predicting the clutch's operating efficiency by Zhou et al., [9] as well.

There are many reasons of power losses in clutches as fluid's leakages in hydraulic clutches from their pumps, valves and seals. Additionally, losses related to the "spin loss" phenomenon in clutches decreases their efficiency. Moreover, the drag on the transmission related to volatile of lubricant oil drops between the rotating elements of wet clutch decreases the clutch efficiency. Power Loss predictions related to churning and volatile of lubricant fluid drops between the rotating elements is discussed by Changenet et al., [10].

Several researchers have also concentrated on the transmission accuracy and the reasons of power loss in modern electric clutch for improving its performance as presented by Gao et al., [11]. Moreover, position control scheme using a triple-step nonlinear method has been presented for the position tracking control of an electric clutch actuator. Design and analysis of a permanent magnet bi-stable electromagnetic clutch in automobile drives presented by Cai et al., [12]. They showed that the capacitor supply at the low power is very agreeable for the bistable electromagnetic clutch. Their experimental results supported the same opinion. Also, practical issues of permanent magnets usage in eddy current brakes discussed by Thompson [13].

Finally, most of the clutches types have some undesired effects such as the partial loss of the transmission power due to friction effect resulted from direct contact in clutches elements. Also, drag torque and the loss of power related to the "spin loss" phenomenon in wet clutches significantly affect the power transmission efficiency. Moreover, delay of hydraulic clutches response reduces demand on acquisition of this type of clutches. Besides, fluctuation of the clamping forces over clutch disks causes many troubles for driving smoothness. In addition, repeatable occurrence of the clamping forces fluctuation increases the clutch wear rate. Hence, probability of sudden troubles confrontation increases the driving hazardous.

This paper is a trail to submit apreliminaryidea and a simple clutchkinematic study of that has a very low friction using permanent magnets, cams and planetary gear trainprovided with a suitable lubricant for reducingpower lossesThis low friction clutch . works without direct contact of friction disks which saves some of the wasted energy in their equivalent .disks of the regular clutches The proposed clutch uses the magnetic forces effect of permanent magnetic cylinders instead of the direct contact effect of the regular clutch's friction disks. In addition, these magnetic forces of permanent magnetic cylinders can be used as a source of clamping forces for decreasing rotational speed of the suggested planetary gear train arrangement. Meanwhile, cams mechanism can be used for assuring that motion is completely stopped. Additionally, permanent magnetic cylinders usage saves the required electricity needed in coils of electro-magnetic clutches. Furthermore, planetary gears of the suggested clutch decrease the output rotation speed and increase transmission torque as an initial reduction gear box. Complicated maintenance is not needed for such kind of suggested clutch. A prototype of this clutch has been also built for testing the proposed conceptual design validity.

\section{The Basic IDEA of the Suggested System}

Figure (1) shows the planetary gear train arrangement which consists of a ring gear, sun gear, two planet gears and planetary arm in addition to a magnetic break with its arm and cams mechanism. These gears are spur gears. When sun gear's shaft rotates with an input motion, the planetary gear train has two degrees of freedom as two options for this arrangement usage. These options are the possibilities that the ring gear or the planetary arm (carrier) can freely rotate. The first option is using this planetary gear train arrangement as a reduction gear box. The second option is using it as a low friction clutch. The magnetic break and cams mechanism can be used as tools for switching between the two previous options. Using planetary gear train as a reduction gear box occurs when the planetary arm's shaft rotates carrying output motion meanwhile magnetic break and cams keep ring gear immobile. On the other hand, using planetary gear train as a clutch occurs when the magnetic break and cams keep planetary arm's shaft 
stationary and give free rotating chance to ring gear. The accuracy of the gear's manufacturing process is the main effective factor for achieving a minimal power loses which is associated with the gear train usage. Power losses model of planetary gear train presented by Nutakor et al., [14] for wind turbine's gearbox. Moreover, new suggested design of planetary gear train tooth, in which sun gear designed with special tooth while the ring gear's tooth as conical grooves in (Cheng and Liang, [15]).

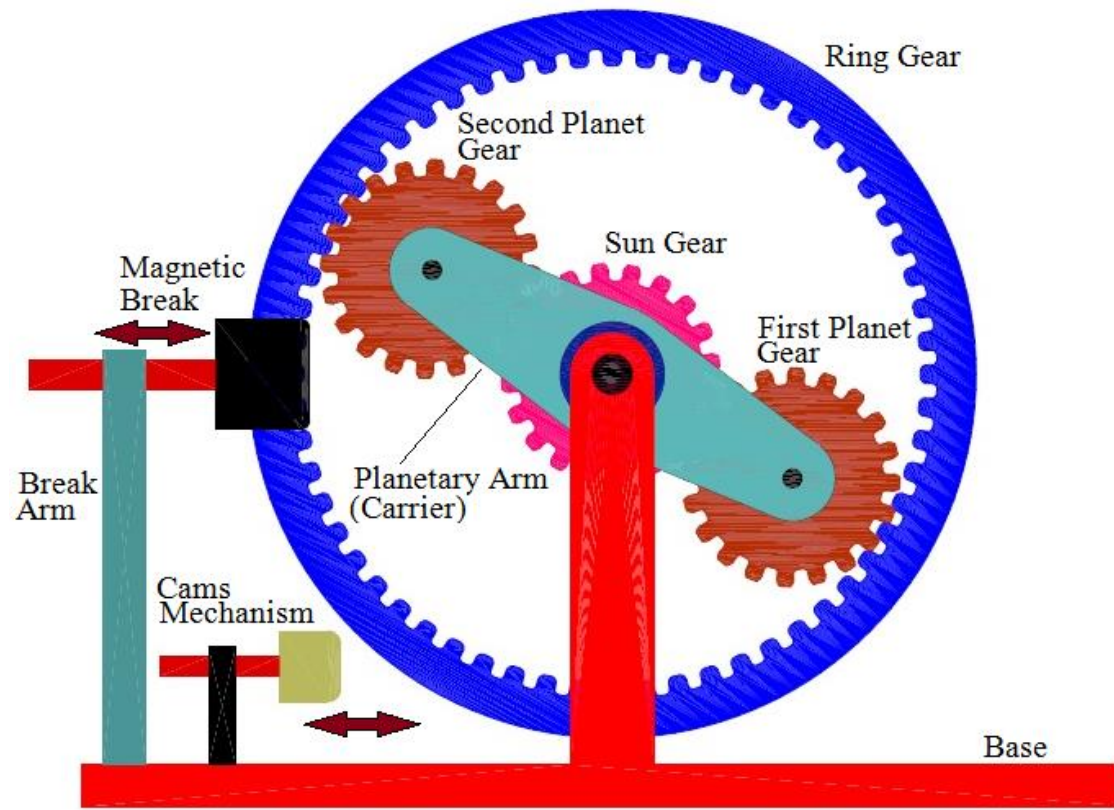

Figure 1 -Arrangement of Planetary Gear Train, Magnetic Break and Cams Mechanism

\section{Proposed Design Using Inventor Software package}

A comprehensive three dimensional of the mechanical design and simulation of the suggested low friction clutch have been created using Autodesk-Inventor Software [16]. The suggested clutch system consists of a planetary gear train, magnetic break and cams mechanism. Figure (2) shows the frontal elements of low friction clutch. Figure (3) shows the other elements of the low friction clutch as well.

\subsection{Frontal Elements of the Suggested System}

Figure (2) shows the frontal elements of the low friction clutch. These elements are planetary gear train in addition to a magnetic break with its arm and cams mechanism for controlling the ring gear motion. The gear train consists of sun gear, ring gear, two planet gears and planetary arm with its holder. Furthermore, permanent magnets cylinders are implanted in ring gear as the first part of the magnetic break. The permanent magnets plates are fixed in the break arm as a second part of the magnetic break. After the magnetic break slows down the ring gear rotation motion till a very low rotation speed, both cams of mechanism clamp the rough surface of ring gear edge for keeping it stationary. Hence, this arrangement can operate as low friction clutch without using any friction disks. Meanwhile, the planetary arm rotates freely around the input shaft carries output motion. Hence, low friction clutch arrangement works as a reduction gear box.

\subsection{Elements at the Backside of the Suggested System}

Figure (3) shows the elements of the low friction clutch at the backside. These elements are disk mounted with the planetary arm in addition to a magnetic break with its arm and cams mechanism for controlling rotation motion of this disk. Permanent magnets cylinders are implanted in disk as the first part of the magnetic break. In addition the other permanent magnets plates are fixed in break arm as the second part of the magnetic break.

After the magnetic break slows down the disk's motion till a very low rotation speed, cams mechanism of the disk clamp the rough surface of disk's edge for keeping it completely immobile. Meanwhile, the ring gear rotates without transmitting input motion to the output shaft. Therefore, this arrangement works as a low friction clutch for separating the transmission motion. 


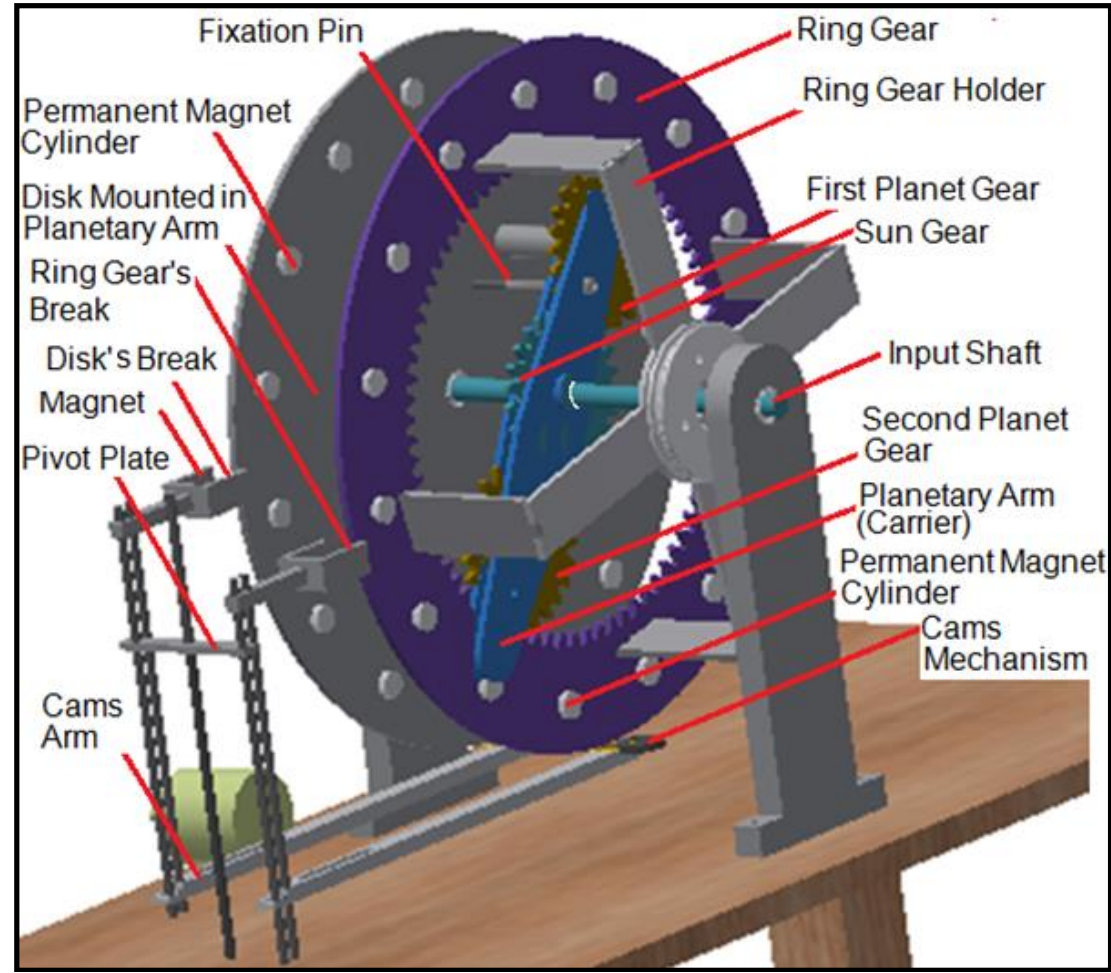

Figure 2 -Frontal Elements of the Low Friction Clutch

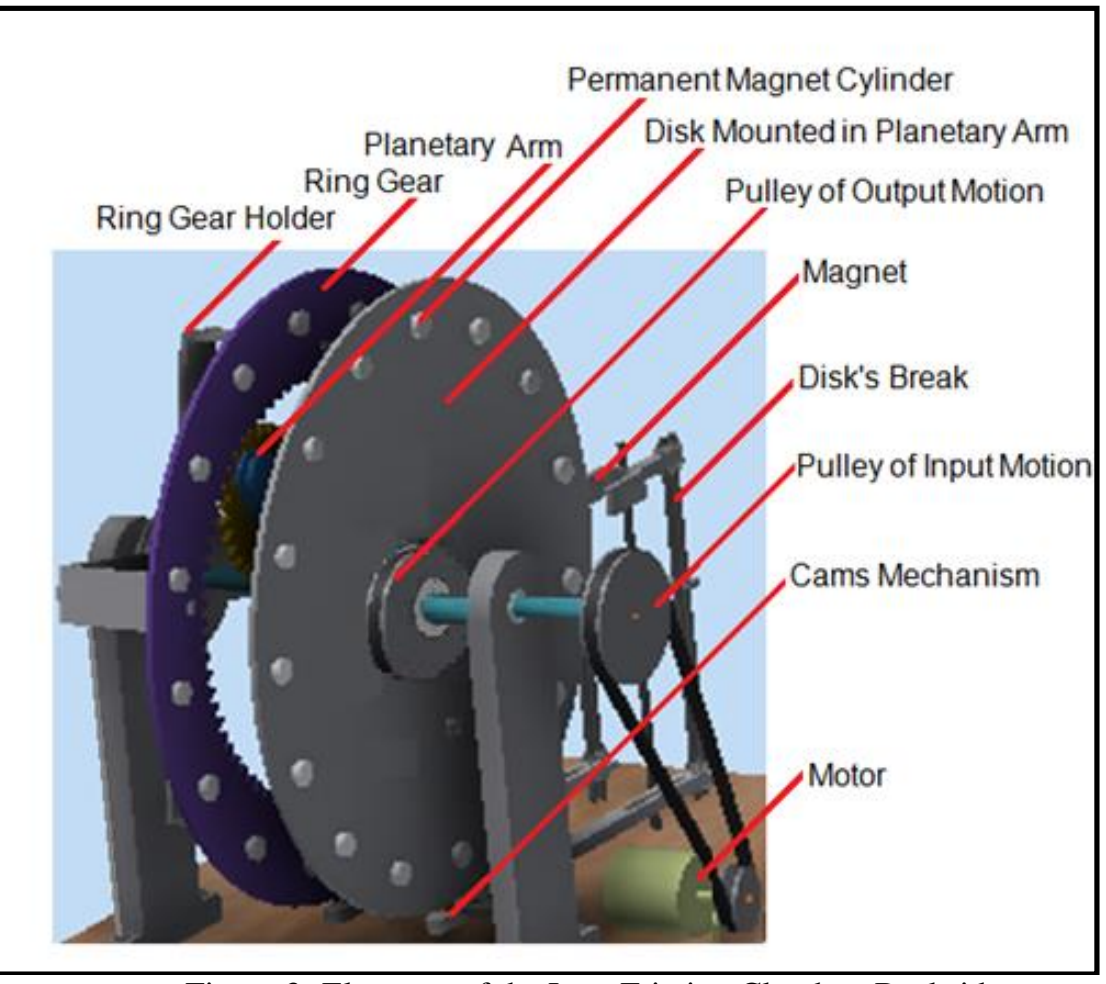

Figure 3 -Elements of the Low Friction Clutch at Backside 



\section{Suggested System Analysis}

Magnetic break and cams mechanism are effective tools for switching between the two cases of the suggested system usage. The first case is the using it as a reduction gear box for reducing the rotational speed and increasing the output torque. The second case is the using it as a low friction clutch for separating the transmission motion.
Figure (4) indicates the switching method using the magnetic break and cams mechanism. Clearly, pivot plate reverses working actions of the magnetic break's arm of ring gear and the other arm of the disk. In addition, engagement of magnetic break for holding ring gear's surface is associated with releasing disk surface from cams mechanism.

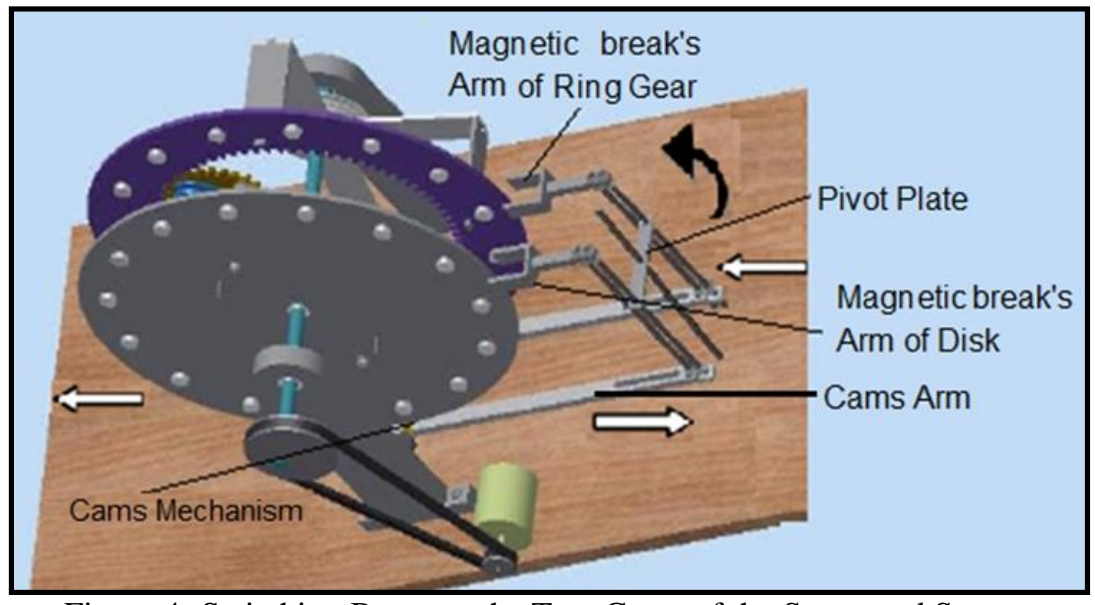

Figure 4 -Switching Between the Two Cases of the Suggested System

\subsection{Planetary Gear Train}

Planetary gear train is one of the main parts of the suggested system. It reduces the input rotational speed and increases the output torque. Moreover, magnetic breaks and cams mechanisms are axillary parts.

Planetary gear train analysis has been presented by Levai [17]. The reduction speed ratio of the suggested system can be calculated using the following equations;

$$
D_{R}=D_{S}+2 D_{P}
$$

Where; $\left(D_{R}\right),\left(D_{S}\right)$ and $\left(D_{P}\right)$ are the pitch diameters of the ring gear, sun gear and planet gear respectively.

Assuming that $\left(T_{R}\right),\left(T_{S}\right)$ in addition to $\left(T_{P}\right)$ are tooth number of ring gear, sun gear and planet gear respectively. Hence, equation dealing with tooth numbers can be formulated as follows;

$T_{R}=T_{S}+2 T_{P}$

(2)

Assume $(m)$ is the tooth module. Hence, the module $(m)$ of ring gear can be calculated as;

$$
m=\frac{D_{R}}{T_{R}}
$$

Planetary gear train reduction ratio was discussed when dealing with tooth number of ring, sun and planet gears by Myszka [18].
Assuming that $\left(n_{R}\right),\left(n_{S}\right)$ and $\left(n_{A}\right)$ are the number of revolutions per minute of ring gear, sun gear and planet gears arm respectively. Hence, equation dealing with number of the revolutions per minute of the system can be written as follows;

$$
\left(T_{S}+T_{R}\right) n_{A}=T_{S} n_{S}+T_{R} n_{R}
$$

Hence, the following equation can be formulated as follows;

$$
\frac{T_{R}}{T_{S}}=\frac{n_{A}-n_{S}}{n_{R}-n_{A}}, \text { where, } n_{R} \neq n_{A}
$$

Using equation (2), the pervious equation can be rewritten again as follows;

$$
f n_{S}=2(f+1) n_{A}-(f+2) n_{R}
$$

Where;

$$
f=\frac{T_{S}}{T_{P}}
$$

When the ring gear is immobile (i.e. $n_{R}=0$ ), equation of the reduction ratio $\left(n_{A} / n_{S}\right)$ can be written as follows; 


$$
\frac{n_{A}}{n_{S}}=\frac{f}{2(f+1)}
$$

\subsection{Magnetic Break}

Attraction magnetic force between two permanent magnets is the main effective parameter of magnetic break efficiency. An approximate magnetic force $\left(F_{A}\right)$ between two permanent magnets cylinders for distance $(x)$ in axial direction can be calculated as presented by Vokoun et al., [19] as follows;

$$
F_{A} \approx \frac{\pi}{2} k R^{4}\left(\frac{1}{x^{2}}+\frac{1}{(x+2 y)^{2}}-\frac{2}{(x+y)^{2}}\right)
$$

Where, $(R)$ is the radius of the permanent cylindrical magnet, $(y)$ is the height of cylinder and the value of $(k)$, which is the magneto-static energy constant, can be calculated using the following equation;

$$
k=\frac{\mu}{2} M^{2}
$$

Where, $(\mu)$ is the permeability of vacuum has a value around (1.25) and $(M)$ is the saturation magnetization in $(\mathrm{MA} / \mathrm{m})$.

Also, a manual method for evaluating an approximate value of permanent magnet's force introduced by Vorohobov [20], to calibrate small magnet using additional iron block of known weight and plastic bar with a certain thickness.

\subsection{Cams Mechanism}

Figure (5) shows the cams mechanism arrangement. Cams mechanism consists of cams holder (arm), two eccentric cams with their arms, inner spring and two outer springs. Clearly, through engaging magnetic break for slowing down the rotational speed of ring gear, cams mechanism must firmly clamp over the ring gear surface's edge. Likewise, through engaging magnetic break for slowing down the rotational speed of disk, cams mechanism must firmly clamp over the disk surface's edge. Also, ring gear breaking process must be associated with disk releasing process. Similarly, disk breaking process must be associated with ring gear releasing process.

When the cams holder (arm) moves towards the ring gear till touching its rough surface edge, the two eccentric cams start to catch the ring gear surface. Furthermore, eccentric effect of cams increases clamping force. Likewise, once the cams holder moves away from the ring gear, the two eccentric cams start to release the ring gear. Moreover, the two outer springs quickly assist cams releasing.

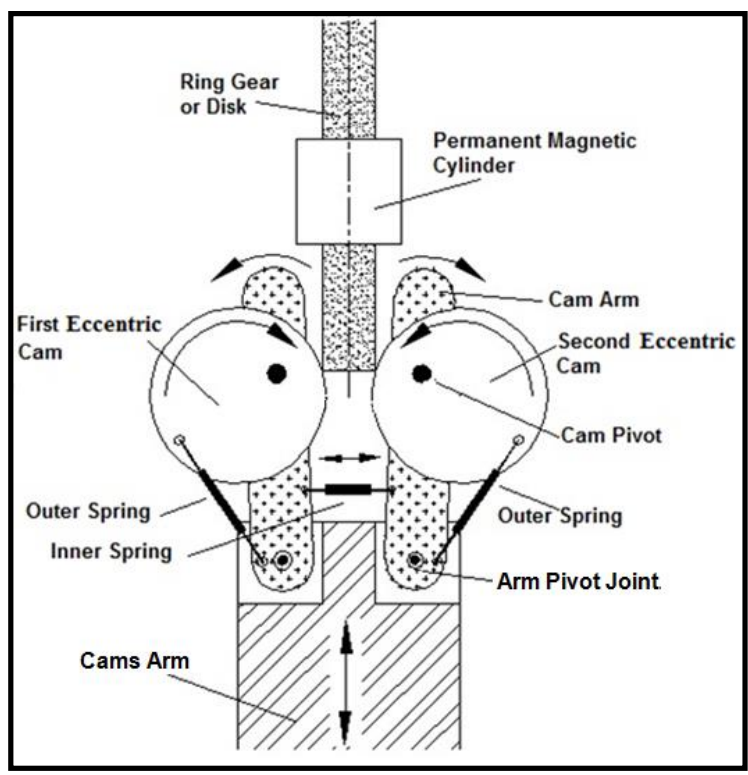

Figure 5 -Cams Mechanism

\section{Prototype of Suggested Low Friction Clutch}

Prototype of the suggested clutch has been built for testing the proposed conceptual design validity. Figure (6) shows both of the frontal view of suggested clutch's elements and the other side view of this clutch.

Prototype elements such as gears, arms, holders, stands, pulleys and cams are fabricated using CNC leaser cutting from Acrylic material have a thickness equals to 10 millimeters. This prototype is provided with 30 cylinders from Neodymium-Iron boron magnet of model (M-35M, TC888). The diameters $D_{S}, D_{P}$ and $D_{R}$ are 100,100 and $300 \mathrm{~mm}$, respectively. Tooth number $T_{S}, T_{P}$ and $T_{R}$ were 25,25 and 75 tooth, respectively. Hence, using equations (7 and 8), the reduction ratio is about $(1: 4)$.

\section{Validity of the proposed conceptual design}

The present prototype indicates that the suggested system is valid for using it as a low friction clutch. Furthermore, planetary gear train works as a reduction gear box with ratio equals to (1:4) when planetary arm's shaft rotates carrying output motion and ring gear is immobile. Also, this gear train can be used as a clutch in case of planetary arm's shaft is immobile, meanwhile ring gear rotates freely. Reduction ratio is measured using (DT2236B Digital Laser Photo Tachometer, with accuracy: $\pm 0.05 \%+1$ digit) as shown in figure (7). This device is used to determine the input and the output angular velocities in revolutions per minute. 


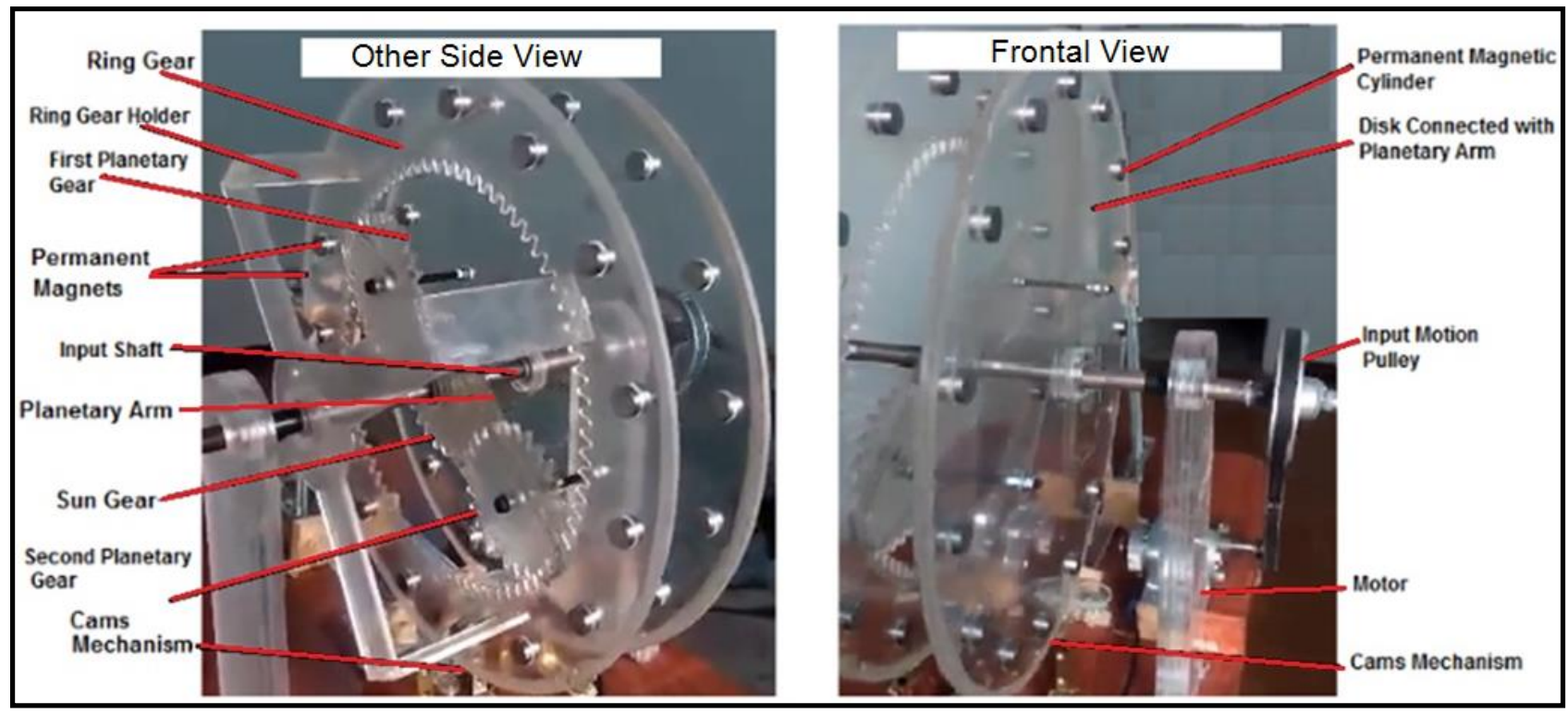

Figure 6 -Prototype of the Suggested System

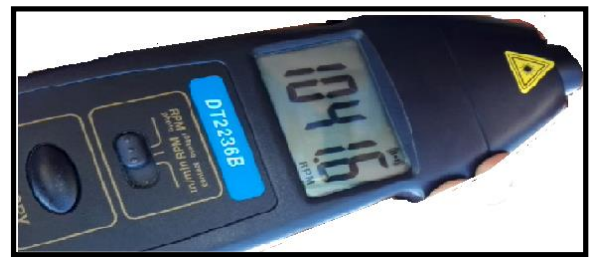

Figure 7 -Digital Laser Photo Tachometer

Figure (8), shows the relation between the measured input and output angular velocities in addition to the theoretical ones of the suggested system. Moreover, the measured and theoretical reduction ratio of the suggested system has a constant rate. As well as, the measured angular velocities reveal a constant reduction ratio equals to (1:4) which is similar to the theoretical ones.

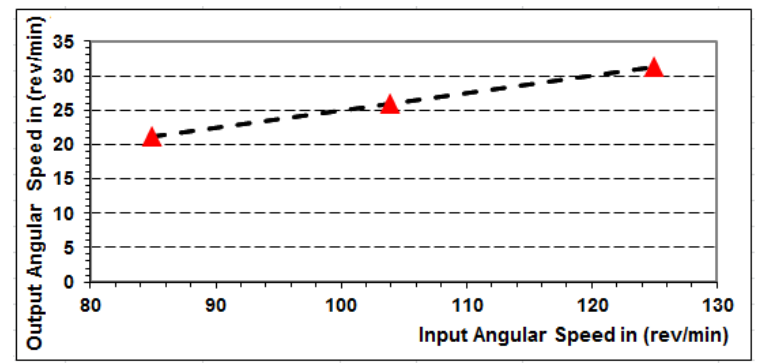

Figure 8 -Input and Output Angular Velocities of the Suggested System

\section{Conclusions}

Motors fuel is playing an important role in vehicles industries development. Unfortunately, ensuring stable availability of fuel is one of the major challenges due to the rapid depletion of fossil fuels. Therefore, controlling power losses is the main concern of the specialists in the automotive industry fields.

This paper presented a preliminary idea for low friction clutch using permanent magnets, planetary gear train and cams mechanisms which reduce the loss of the transmitted power. This clutch uses the magnetic forces of permanent magnets instead of the direct contact action of the regular clutch's friction disks. Also, this clutch is provided with cams mechanism for assuring that ring gear or planetary arm of gear train is completely stationary. Moreover, planetary gear train of this clutch can be used as an initial reduction gear box for decreasing rotational velocity and increasing output torque. Complicated maintenance is not needed for this suggested clutch. Also, experimental prototype proofed the validity of the present proposed conceptual design.

\section{References}

[1] Johanson C., and Duffy J., Automatic Transmission and Transaxles, G-W Publisher, Fourth Edition, pp. 149-184, 2015.

[2] Khamlichi A., Bezzazi M., Jabbouri A., Reis P., and Davim J., "Optimizing Friction Behavior of Clutch Facings Using Pinion-Disk Test", International Journal of Physical Sciences, vol. 3, no. 2, pp. 65-70, 2008.

[3] Chopra V., Smith A., and Angeles J., "Electromechanical Clutch Actuator: Design, Analysis and Experiments", Technical Paper, SAE International, 2013. doi:10.4271/201301-2496, http://papers.sae.org/2013-01-2496/.

[4] $\mathrm{Xu}$ W., and King T., "Flexure Hinges for Piezo-Actuator Displacement Amplifiers: Flexibility, Accuracy, and Stress 
Considerations", Journal of Precision Engineering, vol. 19, pp. 4-10, 1996.

[5] Neelakantan V., Washington G., and Bucknor, N., "Model Predictive Control of a Two Stage Actuation System Using Piezoelectric Actuators for Controllable Industrial and Automotive Brakes and Clutches", Journal of Intelligent Material Systems and Structures, vol. 19, no 7, pp. 845-857, 2008.

[6] Kim J., and Choi S., "Adaptive Force Control of Automotive Clutch Actuator System with Self-Energizing Effect", the 18th IFAC World Congress Milano, (Italy) August 28, 2011, pp. 5088-5093.

[7] Jibin H., Zengxiong P., and Shihua Y., "Drag Torque Prediction Model for the Wet Clutches", Chines Journal of Mechanical Engineering, vol. 22, no. 2, pp. 238-243, 2009.

[8] Takagi Y., Nakata H., Okano Y., Miyagawa M., and Katayama N., "Effect of Two-phase Flow on Drag Torque in a Wet Clutch", Journal of Advanced Research in Physics, vol. 2, no. 2, pp.1-5, 2011.

[9] Zhou X., Walker P., Zhang N., Zhu B., and Ruan J., "Numerical and Experimental Investigation of Drag Torque in a Two-Speed Dual Clutch Transmission", Journal of Mechanism and Machine Theory, vol. pp. 79 .2014،63-46

[10] Changenet C., Oviedo-Marlot X., and Velex P., "Power Loss Predictions in Geared Transmissions Using Thermal NetworksApplications to a Six-Speed Manual Gearbox", Journal of Mechanical Design, ASME, vol. 128, pp. 618-625, 2005.

[11] Gao B., Chen H., Liu Q. and Chu H., "Position Control of Electric Clutch Actuator Using a Triple-Step Nonlinear Method", IEEE Transactions on Industrial Electronics, vol. 61, no. 12, pp. 6995-7003, 2014.

[12] Cai W., Gu C., and Hu X., "Analysis and Design of a Permanent Magnet Bi-Stable Electro-Magnetic Clutch Unit for In-Wheel Electric Vehicle Drives", Journal Energies, vol. 8, pp. 5598-5612, 2015.

[13] Thompson M., "Practical Issues in the Use of $\mathrm{NdFeB}$ Permanent Magnets in Maglev, Motors, Bearings and Eddy Current Brakes", Proceedings of the IEEE, vol. 97, no. 11, pp. 1758-1767, 2009.

[14] Nutakor C., Klodowski A., Mikkola A., and Sopanen J., "Simulation Model of Power Losses for Sun and Planet Gear Pair Used in a Wind Turbine Gearbox", The 15th IFToMM
World Congress, Taipei, Taiwan, October, 2015, pp. 1-8.

[15] Cheng Y., and Liang T., "A Planetary Gear Train with Ring-Involute Tooth", Transactions of the Canadian Society for Mechanical Engineering, vol. 32, no. 2, pp. 251-266, 2008.

[16] Inventor-Autodesk, Autodesk Inventor Professional Software Package, Autodesk Products, (2010), simulation part,

http://images.autodesk.com/apac_anz/files/inv entor_professional_detail bro_us1.pdf,

[17] Levai Z., "Structure and Analysis of Planetary Gear Trains", Journal of Mechanisms, vol. 3, pp. 131-148, 1968.

[18] Myszka D., Machines and Mechanisms: Applied Kinematic Analysis, Prentice Hall, New Jersey, USA, Fourth Edition, pp. 290295, 2012.

[19] Vokoun D., Beleggia M., Heller L. and Sittner P., "Magnetostatic Interactions and Forces between Cylindrical Permanent Magnets", Journal of Magnetism and Magnetic Materials, vol. 321, no. 22, pp. 3758-3763, 2009.

[20] Vorohobov V., "Interaction of Cylindrical Magnet with Semi-Space", Journal of Magneto-hydrodynamics, vol. 46, no. 2, pp. 3-13, 2010. 